\title{
Effect of season on early tomato growth and development rates
}

\author{
D. Klapwijk
}

Glasshouse Crops Research and Experiment Station, Naaldwijk, the Netherlands

Accepted: 25 april 1980

Key-words: tomato, early growth, development, effect of season.

\section{Summary}

Over a period of two years, successive batches of tomato plants were raised throughout the year under the best possible conditions in a glasshouse at Naaldwijk (Netherlands). The intervals between the sowing dates and the attainment of different stages in vegetative and reproductive grow th were determined. The ralationship between the season and the growing period is a simple one and may be represented by three curves: a linear increase in the duration of the growing period between 21 September and 21 December, and a linear decrease between 21 December and $21 \mathrm{March}$. The intersection of these curves shows that the largest growing period is around 21 December. The third period from $21 \mathrm{March}$ tot 21 September remains practically constant. The pattern of the relationship between the season and the growing period is maintained over a range of temperatures and light levels. Growth data from the literature for carnations, roses, radish and lettuce under glass could be described in the same way.

\section{Introduction}

The influence of winter growing conditions on the growth rate of glasshouse crops is very great. Quantification of the variations in growth rates caused by the progression of the season poses quite a few problems and complete data series are not usually available in commercial crop production.

In order to determine the growth pattern of plants at a similar stage throughout the year, it is necessary to carry out a series of experiments. In a few cases, for instance in lettuce, there are already sufficient data available from commercial nurseries. These have been used to compile rather complicated relationships between the season and the growing period (van der Hoeven \& Groenewegen, 1970). However, it is also possible to opt for a simple relationship (Klapwijk, 1979) which can also be justified for tomatoes (Klapwijk, 1981a). Information 
concerning the growing period of tomatoes is analysed further in this article and compared to data from the literature on other crops.

\section{Materials and methods}

\section{Plant raising}

A series of tomato sowings was made form Februari 1974 until January 1976. Except for the temperature regimes, the experiment was conducted in the way already described by Klapwijk \& de Lint (1975b). As far as possible, the temperature settings were those used by commercial growers for tomato plant raising. Occasionally, there were temporary variations of a few degrees because of other experiments carried out in the same glasshouse.

On the whole, the following night/day temperatures were maintained: in the spring and summer of 1974 , the temperature levels were rather high, i.e. $25 / 30^{\circ} \mathrm{C}$. In the autumn of 1974 , the levels were decreased tot $20 / 25^{\circ} \mathrm{C}$ and to $17 / 22^{\circ} \mathrm{C}$ from mid-November until mid-February 1975 . After this, the temperatures were about $25 / 30^{\circ} \mathrm{C}$. In November 1975, the temperatures were set at $20 / 20^{\circ} \mathrm{C}$. These levels were maintained until mid-February 1976 when they were altered to $20 / 25^{\circ} \mathrm{C}$.

Continuous $\mathrm{CO}_{2}$ enrichment was applied to approximately $1000 \mu \mathrm{l} / \mathrm{l}$. Plant samples were collected every week and the fresh weights were determined until weights of about $100 \mathrm{~g}$ were reached. Leaf and truss initiation were monitored microscopically by dissection of the apex.

\section{Presentation of the data}

Growth curves were compiled for the fresh weights and truss initiation. In addition, the numbers of leaves present below the first truss were counted and the dates of first flowering were recorded. It was then possible to calculate how many days elapsed between sowing and the following attributes:

a) fresh weight of $0.1,1,10$ and $100 \mathrm{~g}$

b) initiation of first, second and fourth trusses

c) initiation of the 5th, 10th, 15 th and 20 th leaves.

All these growth characteristics were reduced to the same dimension, i.e. days. In order to characterize the seasonal effect, the data were plotted against the mid date as described by Klapwijk (1979): i.e. the duration of the growing periods between two stages was plotted against the date in the middle of the relevant growing period. From these data regression equations were calculated. The days were numbered consecutively through the year. 


\section{Results}

\section{Fresh weight}

If the logarithm of the fresh weights of individual sowings are plotted against time, the curve declines between 10 and $100 \mathrm{~g}$ fresh weight. In autumn the decline between 10 and $100 \mathrm{~g}$ fresh weight is more severe as a result of decreasing amounts of light. In spring however, the curves are lineair till over $100 \mathrm{~g}$ fresh weight because of the increasing a mounts of light.

In Fig. 1 the growing periods to achieve the different fresh weights are presented against the mid date. It is clear that during the period from 21 September until 21 March, the effect of season on growth is the same in all stages. During the summer there is no seasonal effect of any importance. That the relative growth rate shows a decrease with plant age may be deducted from the increased time interval, particularly for the final tenfold weight increase. This holds true in summer as well as in the pattern during the winter.

The correlation coefficients of the curves in Fig. 1 are so high that this presen-

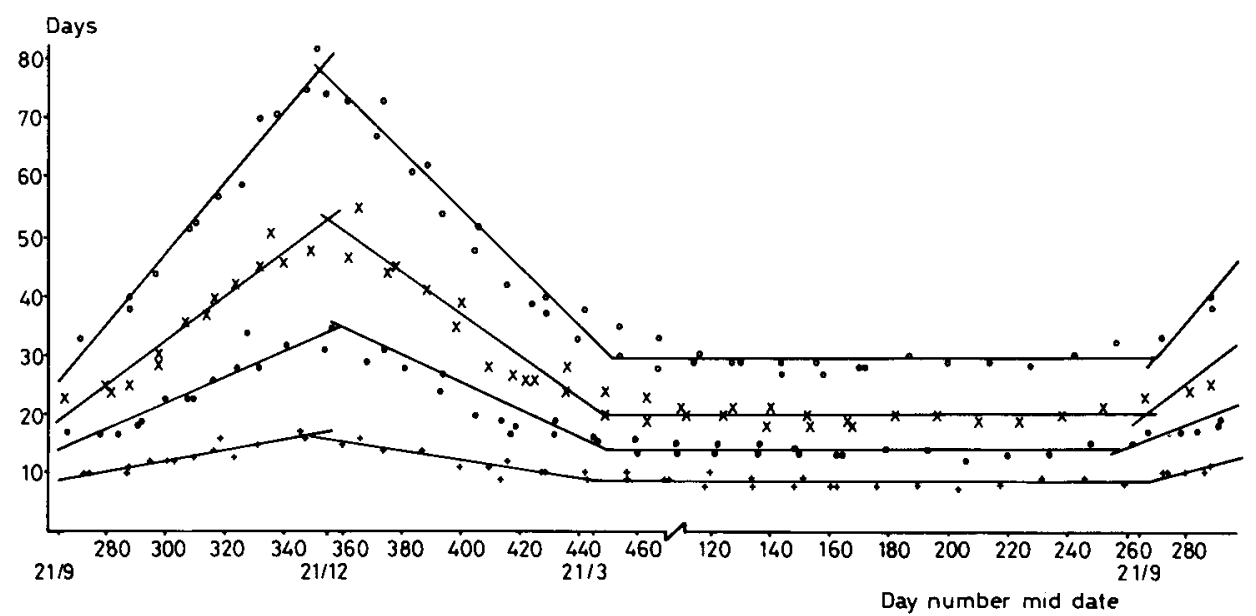

Fig. 1. Number of days from sowing until fresh weights of $0.1 \mathrm{~g}(+), 1 \mathrm{~g}(\mathrm{O}), 10 \mathrm{~g}(\mathrm{x})$ and $100 \mathrm{~g}(\mathrm{O})$.

\begin{tabular}{|c|c|c|c|c|c|c|}
\hline \multicolumn{2}{|c|}{ Autumn (days 264-355) } & \multicolumn{2}{|c|}{ Spring (days 355-445) } & \multicolumn{3}{|c|}{ Summer $(21.3-21.9)$} \\
\hline $\begin{array}{l}\text { regression } \\
\text { equation }\end{array}$ & $r$ & $\begin{array}{l}\text { regression } \\
\text { equation }\end{array}$ & $\mathbf{r}$ & $\begin{array}{l}\text { average } \\
\text { (days) }\end{array}$ & $\begin{array}{l}\text { stand. } \\
\text { dev. }\end{array}$ & $\begin{array}{l}\text { var. } \\
\text { coeff. }\end{array}$ \\
\hline
\end{tabular}

$+y=0.0940 x-16.1$

$0.946 y=-0.0779 x+43.3$

$0.904 \quad 8.6$

$0.953 \quad 14.0$

0.76

(\%)

$y=0.2208 x-44.1$

$0.932 y=-0.2187 x+111.1$

0.99420 .1

1.03

8.9

$x y=0.3746 x-80.0$

$0.972 y=-0.3694 x+183.9$

$0.975 \quad 29.5$

1.54

7.3

O $y=0.5902 x-130.0$

$0.985 y=-0.5166 x+260.4$

1.96

7.7

6.7 


\section{KLAPWIJK}

tation may be regarded as an accurate estimate of the growing periods throughout the year. Although some data in this graph and subsequent ones seem to show a more or less sinusoidal pattern, the linear relation was chosen; it is simple and not contradicted by other available data.

\section{Leaf initiation}

The rate of leaf initiation varied from 3.85 to 1.37 days per leaf. Fig. 2 shows the data for the growing periods up to a certain leaf stage in the same way as the fresh weight data presented in Fig. 1.

The correlation coefficients for the curves of the growing periods between sowing and initiation of the fith leaf are slightly lower, but they are still very satisfactory considering the shallow slope. For the later stages the correlation coefficients are $>0.95$.

The distance between the curves are pratically the same at every point in time, as a result of the even rate of development over the whole range from the 5 th to the 20 th leaf. For any given sowing date the rate of leaf production was constant.

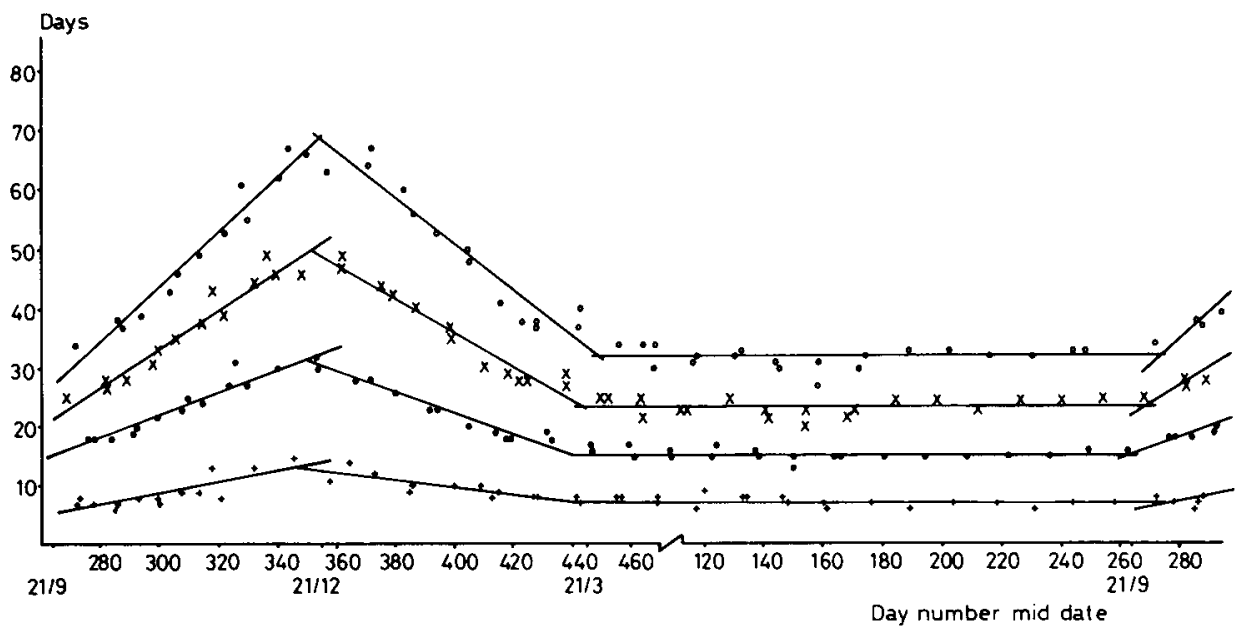

Fig. 2. Number of days from sowing until the initiation of the fifth $(+)$. tenth $(\mathbf{O})$. fifteenth $(x)$ and twentieth $(O)$ leaf.

\begin{tabular}{|c|c|c|c|c|c|c|c|}
\hline \multicolumn{3}{|c|}{ Autumn (days 264-355) } & \multicolumn{2}{|l|}{ Spring (days $355-445$ ) } & \multicolumn{3}{|c|}{ Summer $(21.3-21.9)$} \\
\hline & $\begin{array}{l}\text { regression } \\
\text { equation }\end{array}$ & $r$ & $\begin{array}{l}\text { regression } \\
\text { equation }\end{array}$ & $r$ & $\begin{array}{l}\text { average } \\
\text { (days) }\end{array}$ & $\begin{array}{l}\text { stand. } \\
\text { dev. }\end{array}$ & $\begin{array}{l}\text { var. } \\
\text { coeff. } \\
(\%)\end{array}$ \\
\hline+ & $y=0.0990 x-21.0$ & 0.856 & $y=-0.0592 x+33.4$ & 0.858 & 7.2 & 0.86 & 11.9 \\
\hline & $y=0.1915 x-35.5$ & 0.950 & $y=-0.1786 x+93.8$ & 0.967 & 15.4 & 0.93 & 6.0 \\
\hline & $y=0.3244 x-63.8$ & 0.969 & $y=-0.2881 x+151.3$ & 0.971 & 23.5 & 1.31 & 5.6 \\
\hline 0 & $y=0.4615 x-94.8$ & 0.981 & $y=-0.3863 x+205.4$ & 0.955 & 31.9 & 1.73 & 5.4 \\
\hline
\end{tabular}




\section{Truss initiation and anthesis}

The rate of truss initiation varied from 16.6 days between two trusses in midwinter to 4.4 days per truss during summer.

Fig. 3 shows the annual pattern of truss initiation in various stages. It also shows the periods between sowing and anthesis. The distances between the truss initiation curves are practically the same as a result of the constant growth rates. Opening of the first flower coincided with the time at which the fourth truss could be observed microscopically in the apex of the plant. As was the case with leaf initation, the correlation coefficients were rather low in the earliest stage, but improved for the later stages, indicating that the trends are significant.

\section{Discussion}

\section{Effects of the season in winter}

In the weight increases, leaf and truss initiation, as well as in flowering, similar patterns were found for the relationship between season and the growing pe-

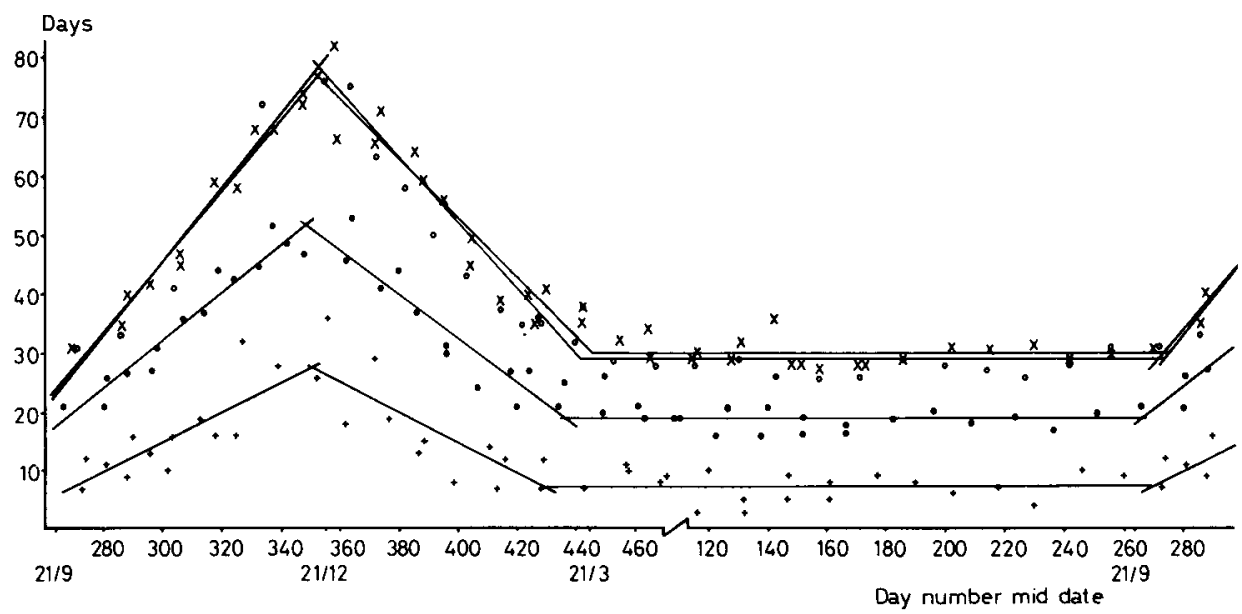

Fig. 3. Number of days from sowing until the beginning of truss initiation $(+)$, until the second $(0)$ and fourth $(x)$ trusses were observed and until opening of the first flower $(O)$.

\begin{tabular}{|c|c|c|c|c|c|c|c|}
\hline \multicolumn{3}{|c|}{ Autumn (days 264-355) } & \multicolumn{2}{|l|}{ Spring (days 355-445) } & \multicolumn{3}{|c|}{ Summer (21.3-21.9) } \\
\hline & $\begin{array}{l}\text { regression } \\
\text { equation }\end{array}$ & $\mathrm{r}$ & $\begin{array}{l}\text { regression } \\
\text { equation }\end{array}$ & $\mathrm{r}$ & $\begin{array}{l}\text { average } \\
\text { (days) }\end{array}$ & $\begin{array}{l}\text { stand. } \\
\text { dev. }\end{array}$ & $\begin{array}{l}\text { var. } \\
\text { coeff. } \\
(\%)\end{array}$ \\
\hline+ & $y=0.2545 x-61.3$ & 0.828 & $y=-0.2566 x+117.4$ & 0.798 & 7.3 & 2.52 & 34.4 \\
\hline 0 & $y=0.4037 x-88.8$ & 0.967 & $y=-0.3735 x+182.1$ & 0.922 & 19.0 & 2.36 & 12.4 \\
\hline $\mathrm{x}$ & $y=0.5913 x-131.9$ & 0.985 & $y=-0.4972 x+251.9$ & 0.945 & 29.9 & 2.25 & 7.5 \\
\hline $\mathrm{O}$ & $y=0.6238 x-141.6$ & 0.964 & $y=-0.5536 x+273.7$ & 0.903 & 29.0 & 2.78 & 9.6 \\
\hline
\end{tabular}


riods. In all cases, the growing periods in winter could be characterized by two linear functions with an intersection around the mid date of 21 December. This confirms the data published previously (Klapwijk \& de Lint 1975b), the results of growing periods of lettuce in Holland (Klapwijk, 1979) and also those of radish (Klapwijk, 1980).

The relationship is also valid if calculations are carried out with other data from the literature. The results of such calculations are not in conflict with the two-sided linear function in winter although insufficient data have been published concerning the period around the mid date of 21 December which is the most difficult growing period. The relationship in Fig. 3 was found with data published by Copper (1964).

Calvert (1964) gives the results for tomatoes from cotyledon expansion to flowering, but the data are inadequate for the period after mid-February. The relationship was also found with data published by Bunt (1972) carnations.

Data for glasshouse roses published by van den Berg \& Valentin (1978) show the same relationship. The regression equations and correlation coefficients from the different sources are given in Table 1 , where $\mathrm{x}=$ day number of the mid date (1 September $=$ day 1 ) and $y=$ period in days, except for Bunt (1972), in which $y=$ growth rate as a percentage per day.

The data of Table 1 refer to plant weights and various stages of development in a range of crops. They demonstrate that the relationships between season and growing period appear to be similar and apply to all these crops under the growing conditions in the Netherlands and the United Kingdom.

\section{Effects of individual growth factors}

Differences in growing conditions may cause substantial variations in the growing periods, but the seasonal effect maintains the same pattern. Cooper (1964) found growing periods in tomatoes from sowing to anthesis which were 60 to $70 \%$ longer than those in Fig. 3. Apparently the growing conditions caused a much reduced rate of growth. However, in spite of this, the same pattern could be seen in the relationship between the season and the growing period.

The data presented here were not all obtained under constant or optimum growing conditions. The temperature in particular had to be changed for some sowings in order to meet the requirements of other experiments carried out in the same glasshouse. However, the results obtained from these sowings did not detract from the general pattern. In addition the amount of natural radiation in February 1975 was very high and in March it was exceptionally low. This caused some anomalies in the results of the individual sowings, but again it did not upset the general pattern.

Klapwijk (1981a) has determined the seasonal dependency for the growing periods from sowing to $10 \mathrm{~g}$ fresh weight and to the initiation of the 15 th leaf, both 


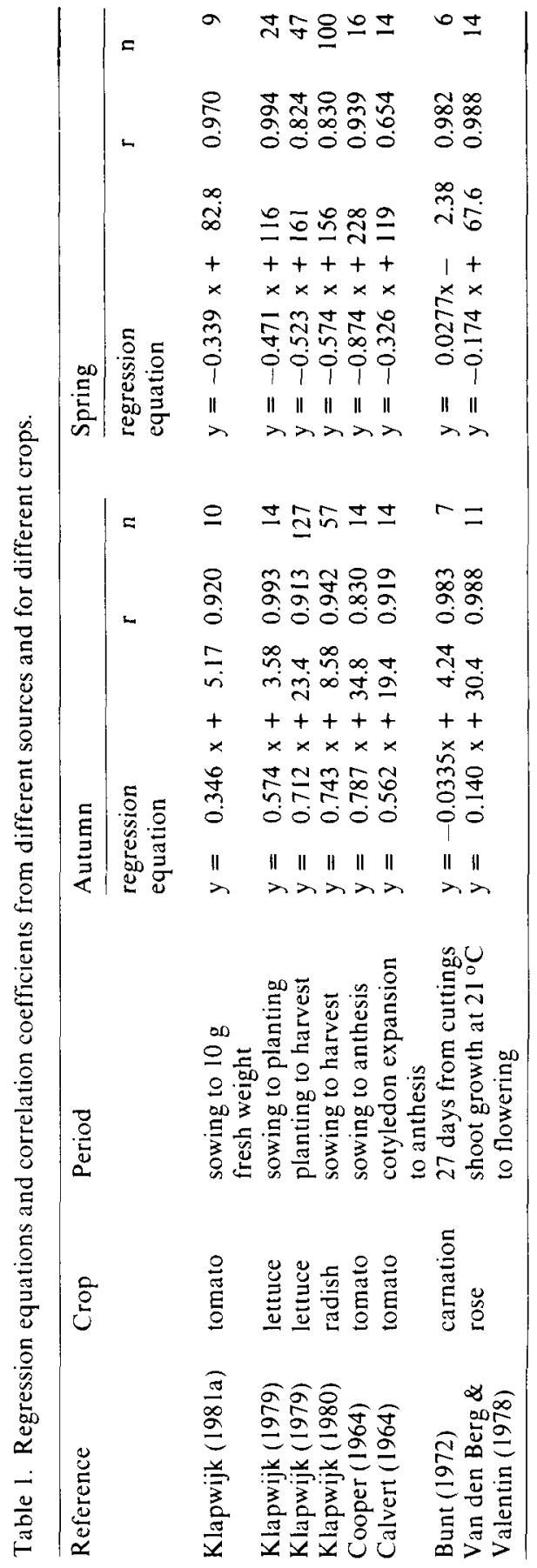

Neth. J. agric. Sci. 29 (1981) 
at two temperature levels 5 "C apart. In both cases, the two-sided linear pattern with a point of intersection around 21 December was maintained. The lower temperature retarded growth by about five days. The relationship for truss initiation was also two-sided linear, but in this case the lower temperature advanced truss initiation since fewer leaves were formed below the first truss.

Van den Berg \& Valentin (1978) measured the growing periods for rose shoots during the winter at four night temperatures, ranging from 12 to $21^{\circ} \mathrm{C}$. The pattern of the relationship between the season and the growing periods was maintained at all temperature levels. In this case, the temperature effect was much greater than that found by Klapwijk (198la) for tomatoes. The latter found a difference in the growing period of about 1 day per ${ }^{\circ} \mathrm{C}$, van den Berg \& Valentin, with a night temperature difference of 12 tot $21^{\circ} \mathrm{C}$ which amounts to an average 24-hour difference of about $5{ }^{\circ} \mathrm{C}$, found a difference of about 4 days per ${ }^{\circ} \mathrm{C}$ for a similar growing period.

Calculations based on the data from Bunt (1972) showed that for carnations the two-sided linear relationship with the point of intersection at around $21 \mathrm{De}$ cember was also maintained when shading was used to reduce the amount of light by $50 \%$. The temperature effects in the investigation by Klapwijk (1981a) have been mentioned, but different light levels were also included in the same experiments. In this case also it was found that the pattern of the seasonal effects was maintained at the different light levels (Klapwijk, 1981b).

\section{Effects of the season in summer}

Previous data by Klapwijk \& de Lint (1975b) showed that between 0.1 and $10 \mathrm{~g}$ fresh weight, the growth rate of tomato plants under glass was constant during the summer, in agreement with Fig. 1.Fig. 2 and 3 show that this holds true also for leaf and truss initiation in the growing point and for the growing period between sowing and flowering.

The amount of radiation in mid-summer is about twice as large as that in March or September. The temperatures under glass in late summer are generally higher than in the early part of the summer. Even with this difference, there was little effect on the growing times during summer. Cooper (1964) also found a constant growth rate in summer, despite much longer growing periods than those given in Fig. 3, which indicates that the growing conditions were much less favourable. Calvert (1964) also found a constant summer value for the flowering of tomatoes in the periods which he defines as cotyledon expansion to anthesis.

In the case of carnations (Bunt, 1972), the growing periods in summer are slightly less constant. In the early summer, the growth rate was slower but the temperature at that time was also much lower than the optimum. This is indicated by Fig. 5 in his paper in which he demonstrates the effects of radiation and temperature on the growth rate, from which one can deduce that the tempera- 


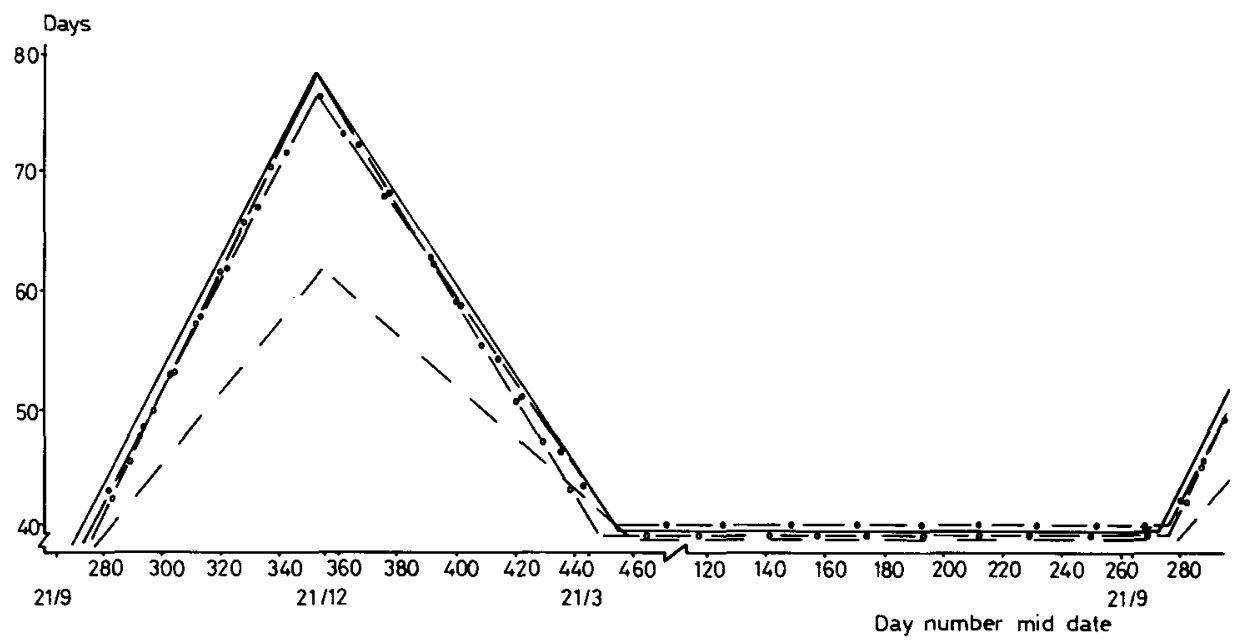

Fig. 4. Number of days from sowing until $100 \mathrm{~g}$ fresh weight (_- until initiation of the fourth truss ( $-\longrightarrow$ ). until the first flower opened $(-\mathrm{O}-$ ). and until initiation of the eighteenth leaf $(-\longrightarrow)$.

ture should have been about $20^{\circ} \mathrm{C}$. This value was not reached by any means during the early summer period.

Comparison of the summer and winter effects

The various plant characteristics are all equally delayed in mid winter compared to mid summer. The summer/winter ratios of times to reach a particular characteristic are $1: 2.66$ for the period from sowing to $100 \mathrm{~g}$ fresh weight, $1: 2.66$ for the period from sowing to the initiation of the 4th truss and 1:2.73 for the period from sowing to anthesis. Vegative and generative developments progress at the same pace throughout the year, as has been demonstrated previously by Klapwijk \& de Lint (1975a). This is also true for the growing period from sowing to initiation of the 18 th leaf in summer, but in winter this period becomes gradually shorter compared with the periods for other characteristics (Fig. 4). This coincides with the gradual diminution of the leaf size in winter. As leaf and truss initiation are coupled, one would expect that truss initiation in winter would also take place relatively earlier. However, there is a compensating increase in the number of leaves formed below the first truss towards mid-winter. The number of leaves below the first truss increased from an average of 7.5 in summer to 11.5 in mid-winter. The 18 th leaf was observed at a maximum of about 62 days after sowing. A leaf was initiated every 3.5 days. With a maximum difference of four leaves below the first truss, this means that truss initiation is retarded by a fortnight which agrees with Fig. 4. 


\section{KLAPWIJK}

\section{Acknowledgement}

The author is greatly indebted to Mrs. C. F. M. Wubben who carried out a large part of the experimental work and to Dr. P. J. A. L. de Lint and Dr. R. G. Hurd for their critical appraisal of the manuscript.

\section{References}

Berg, G. A. van den \& J. C. M. Valentin, 1978. The effects of the night temperature on the winter production of the rose cultivars Sonia and Ilona (Dutch). Bloemisterij onderzoek in Nederland over 1978: 246-253. Research Station for Flower Crops, Aalsmeer, the Netherlands.

Bunt, A. C., 1972. Effect of season on the carnation (Dianthus caryophyllus L.). 1. Growth rate. $J$. hort. Sci. 47: 467-477.

Calvert, A., 1964. Growth and flowering on the tomato in relation to natural light conditions. J. hort. Sci. 39: 182-193.

Cooper, A. J., 1964. The seasonal pattern of flowering of glasshouse tomatoes. J. hort. Sci. 39: 111 119.

Hoeven, A. P. van der \& J. H. Groenwegen, 1970. Sowing, transplanting and harvesting times of lettuce (Dutch). Tuinderij 10: 567-570.

Klapwijk, D., 1979. Seasonal effects of the cropping-cycle of lettuce in glasshouses during the winter. Scientia Hortic. 11:371-377.

Klapwijk, D., 1980. Effect of season on growing period of radish under glass. (Dutch.) Landbouwk. Tijdschr./pt 92 (12) 413-415.

Klapwijk, D., 198 la. Effect of season and temperature on growth and development of young tomato plants. Acta Hortic. 115 (1) 49-58.

Klapwijk, D., $198 \mathrm{lb}$. Effects of season and artificial light on the growth and development of young tomato plants. ISHS symposium on artificial lighting in horticulture (Conthey, Switzerland). Acta Hortic. (in press).

Klapwijk, D., \& P. J. A. L. de Lint, 1975a. Growth and development of young tomato plants. Acta Hortic. 51: 147-161.

Klapwijk, D., \& P. J. A. L. de Lint, 1975b. Growth rates of tomato seedlings and seasonal radiation. Neth. J. agric. Sci. 23: 259-268. 